\title{
A graphenic and potentiometric sensor for monitoring the growth of bacterial biofilms
}

\author{
Noemi Poma ${ }^{1}$, Federico Vivaldi ${ }^{1,2 *}$, Andrea Bonini ${ }^{1}$, Pietro Salvo ${ }^{2}$, Bernardo Melai ${ }^{1}$, Daria Bottai ${ }^{3}$, \\ Arianna Tavanti ${ }^{3}$ and Fabio Di Francesco ${ }^{1}$ \\ 1 Department of Chemistry and Industrial Chemistry - University of Pisa, Italy; \\ n.pomasajama@studenti.unipi.it (N.P); andrea.bonini@phd.unipi.it (A.B); melai@dcci.unipi.it (B.M); \\ fabio.difrancesco@unipi.it (F.D.F). \\ 2 Institute of Clinical Physiology- National Research Council, Italy; pietro.salvo@ifc.cnr.it \\ 3 Department of Biology -University of Pisa, Italy; daria.bottai@unipi.it (D.B), arianna.tavanti@unipi.it (A.T) \\ * Correspondence: federicomaria.vivaldi@phd.unipi.it
}

\begin{abstract}
Biofilm development on surfaces represents one of the most challenging issues in the medical field. The irreversibility of this process, and the characteristics of the biofilm, make biofilm associated infections difficult to treat and prone to relapse. Thanks to the short response time, lowcost, easy fabrication and potential for miniaturization, electrochemical sensors are expected to play an important role in monitoring biofilm formation. Here, we describe the use of a potentiometric sensor based on functionalized reduced graphene oxide for monitoring the formation and growth of biofilms from three bacterial species (Escherichia coli, Pseudomonas aeruginosa and Staphylococcus aureus) in liquid and semisolid culture media. The Open Circuit Potential (OCP) between an $\mathrm{Ag} / \mathrm{AgCl}$ pseudo reference electrode and a working electrode, both screen-printed on a flexible polyethylene terephthalate film, was measured during the growth of bacteria. The OCP decreased over time as bacteria grew on the sensor surface exhibiting a negative correlation.
\end{abstract}

Keywords: Biofilm growth monitoring; Escherichia coli; Pseudomonas aeruginosa; Staphylococcus aureus; functionalized reduced graphene oxide; potentiometric sensor.

\section{Introduction}

Microbial biofilm formation on medical devices and tissues represents an important and still challenging issue [1,2]. Just in the medical field, according to the National Institute of Health $(\mathrm{NIH})$, biofilms are responsible for around $80 \%$ of human microbial infections, considering both device and non-device related diseases [3,4]. Among them, central venous catheter associated infections $[5,6]$, prosthetic joint infections [7,8], osteomyelitis [9], chronic wounds [10-12], lung infection in cystic fibrosis [13] are some common examples. Moreover, biofilm associated infections (Bls) are difficult to treat and prone to relapse, as microorganisms within a biofilm present a highly reduced susceptibility to the host immune system and to antimicrobial compounds (about 1000 times higher if compared to planktonic bacteria) $[14,15]$. Biofilm formation is typically an irreversible process: once the biofilm is formed it cannot be easily eradicated, and in some cases the removal of the entire medical device or of the infected tissue is required [16]. Biofilm development is indeed a major cause of medical device malfunctioning, wound treatment failure [17], localized and systemic infections [18] accounting for a significant increase in patients' morbidity and mortality, with an important economic burden to the health system [15]. Just in the United States, the annual cost associated to blood stream catheter infections is estimated to range between $\$ 300$ million and $\$ 2.3$ billion [19].

Biofilms in Bls are associated to a plethora of different microbial species, but Staphylococcus epidermidis, S. aureus, Pseudomonas aeruginosa and Escherichia coli are the bacterial species most frequently involved [20], whose occurrence depends on the microorganism itself, the substrate characteristics and the availability of nutrients $[4,6]$. Clinical diagnosis of Bls is complex, as it is difficult to discriminate from acute infections associated to planktonic bacteria [21]. Currently, culture-based, molecular approaches and microscopy techniques are commonly used [22]. However, they are timeconsuming, require specialized personnel and, more importantly, are not able to monitor biofilm development in vivo [21]. As a consequence, a sample biopsy or the device excision are often necessary [21]. A number of techniques such as, Peptide Nucleic Acid-Fluorescence in situ hybridization (PNA-FISH) [23,24], Desorption-Electro-Spray-Ionization Mass Spectrometry (DESI- 
MS) [25], Matrix Assisted Laser Desorption/lonization Time of Flight Mass Spectrometry (MALDITOF-MS) $[26,27]$ and others have also been adapted to study biofilm formation, but they are mainly restricted to its characterization, and do not fulfill the urgent need for a real time monitoring and in situ biofilm detection [28]. In this context, the use of sensing devices as monitoring systems represents a worthy alternative, since they may continuously provide information to the health-care personnel. Such devices would indeed contribute to improve patients' quality of life, as an early warning may reduce the adverse effects linked to the progression of the infection and consequently reduce both the hospital stay time and treatment costs.

So far, biofilm sensing systems mainly based on optical and electrochemical transduction have been proposed. Optical devices encompassing optic fiber [29,30], surface plasmon [31], fluorescence methods [32] and others are based on the measurement of the increase in the layer thickness, the metabolic activity, the biofilm chemical composition and the presence of single chemical species [33]. Devices to monitor biofilm growth in situ have been designed, but their application has been mainly focused in the environmental and industrial area. Strathmann et al. described the development of a non-destructive optical sensor, with a limit of detection of $10^{6}$ bacterial cells $/ \mathrm{cm}^{2}$, aimed to be integrated in water pipes. This device used fluorescence and light scattering to distinguish abiotic deposits and biofilm, whose presence was estimated from the autofluorescence of two indicators, namely tryptophan (biomass content) and NADH (biological activity) [34]. The development of a colorimetric smart dressing prototype to assess bacterial colonization in wounds has been described. The device consisted of an hydrated agarose film containing 5,6-carboxyfluorescein dye vesicles released in the presence of virulence factors produced when $P$. aeruginosa, $S$. aureus and Enterococcus faecalis grew as a biofilm in an ex-vivo model [35]. The fluorescence response of this system was obtained using a microplate reader, making this approach not suitable for a continuous monitoring.

Electrochemical sensors are promising for their short response time, low-cost, simple fabrication, high sensitivity and possibility of miniaturization [36]. Most electrochemical sensors described in literature measure changes of impedance, which are attributed to biofilm growth and lead to variations in the capacitance, in the solution resistance or in both. Muñoz-Berbel et al. detected the biofilm growth of $P$. aeruginosa on a gold-chip working electrode, where the Constant Phase Element (CPE) decreased as the number of bacteria on the electrode surface increased [37]. In another paper, the monitoring of biofilm growth using gold-interdigitated electrodes in 96-well plates and Petri dishes was associated to a change in the solution resistance reflecting the whole metabolic activity of the biofilm [38]. Huiszoon et al. described a flexible impedance-based sensor capable of monitoring the growth of $E$. coli in the lumen of a urinary catheter [39]. Voltammetry has also been used to detect the bacterial colonization of a surface, expressed as a change in the electroactive area. Kang et al. described the use of the Cyclic Voltammetry (CV) and the redox couple ferrocyanide-ferricyanide to calculate the surface coverage and individuate adhered $P$. aeruginosa PAO1 [40]. The detection of electroactive species such as pyocyanin, a phenazine naturally produced by $P$. aeruginosa, has also been considered. Bellin et al. described how to use Square Wave Voltammetry (SWV) to quantify the phenazines produced by $P$. aeruginosa with a detection limit of $2.5 \mu \mathrm{M}$ [41]. However, this approach is restricted to the detection of this bacterium.

Potentiometric sensors for biofilm detection and characterization have also been developed; they present many advantages if compared to other electrochemical techniques, as they do not need an external source of power and are easy to use. Here, the open circuit potential (OCP) between a working and a reference electrode is measured to assess the analyte concentration/activity. The OCP transduction has long been used in the study of electrochemically active biofilms in marine ecosystems, where a change in the OCP may be associated to the biofilm biomass $[42,43]$. Potentiometric needle microsensors are also used to study biofilms without perturbing the system. Guimerà et al. developed an ion-selective microsensor for monitoring $\mathrm{pH}$ gradients within a biofilm [44], but fragility and need of constant calibration limit the use of needle microsensors to carefully performed research studies.

The present work describes the development of a potentiometric sensor capable of monitoring bacterial colonization and biofilm formation in liquid and semisolid culture media of three bacterial species commonly associated to the development of Bis, namely Escherichia coli, Pseudomonas 
aeruginosa and Staphylococcus aureus. This device exploited the chemical and electrical properties a graphene derivative as a sensing layer. The OCP changes in the presence of bacteria were continuously and efficiently recorded to allow a rapid sensing of the growing biofilm biomass. Flexibility of the sensing board makes it suitable to challenging applications related to human health, e.g. monitoring of biofilm development in medical devices (i.e. lumen of catheters) and in chronic wounds.

\section{Materials and Methods}

\subsection{Sensing board}

The sensor was fabricated using the screen-printed electrodes described by Salvo et al. [45]. The board consisted of a flexible support of polyethylene terephthalate (PET, $125 \mu \mathrm{m}$ thick) with silver signal tracks. This contained four graphite working electrodes (WEs, layer thickness $16 \mu \mathrm{m}$, diameter $2 \mathrm{~mm}$ ) and an $\mathrm{Ag} / \mathrm{AgCl}$ pseudo reference electrode (RE, layer thickness $20 \mu \mathrm{m}$, diameter $1 \mathrm{~mm}$ ). The board was totally passivated with a polyester resin ( $30 \mu \mathrm{m}$ thick), except for the WEs and RE areas.

\subsection{Graphene oxide reduction and functionalization}

Graphene oxide (GO) reduction and functionalization were performed as previously described [46,47]. Briefly, a $4 \mathrm{~mL}$ GO solution $4 \mathrm{mg} / \mathrm{mL}$ (C: 49-56\%; O: 42-50\%, H: 0-1\%; N: 0-1\%; S: 2-4\%) (Graphenea), was reduced with $0.3108 \mathrm{~g}(0.45 \mathrm{M})$ of L-ascorbic acid (LAA, A7506) (Sigma Aldrich). The solution was then kept at $80^{\circ} \mathrm{C}$ for $4 \mathrm{~h}$ until a black dispersion was obtained. Once at room temperature, $0.1645 \mathrm{~g}(0.3 \mathrm{M})$ of 4-aminobenzoic acid (100536) (Sigma Aldrich) and $0.1655 \mathrm{~g}(0.6 \mathrm{M})$ sodium nitrite (372109) (Carlo Erba) were added and the dispersion stirred at $80^{\circ} \mathrm{C}$ for $12 \mathrm{~h}$. The dispersion was then cooled to room temperature and filtered through a polyamide membrane filter Whatman ${ }^{\circledR}$ (WHA10414012, pore size $0.2 \mu \mathrm{m}$, membrane diameter $47 \mathrm{~mm}$ ), and then rinsed three times with deionized water. Finally, the solid was dispersed in $8 \mathrm{~mL}$ of deionized water and a final concentration of about $1 \mathrm{mg} / \mathrm{mL}$ was obtained.

\subsection{Sensor fabrication}

Each working electrode was electrochemically cleaned before the sensor fabrication. A cyclic voltammetry ( 5 cycles, step $0.009 \mathrm{~V}$, scan rate $0.1 \mathrm{~V} / \mathrm{s}$ ) range $-0.6 \mathrm{~V}$ to $0.6 \mathrm{~V}$ vs pseudo $\mathrm{Ag} / \mathrm{AgCl}$ reference electrode in a $5 \mathrm{M} \mathrm{NaCl}$ solution with a platinum electrode as auxiliary electrode.

After the cleaning procedure, the WEs were previously functionalized by the electrodeposition of 4-aminobenzoic acid diazonium salts. Cyclic voltammetry was performed (5 cycles, step $0.009 \mathrm{~V}$, scan rate $0.1 \mathrm{~V} / \mathrm{s}$ ) range $[0.3,-1.4] \mathrm{V}$ vs pseudo $\mathrm{Ag} / \mathrm{AgCl}$ reference electrode in an aqueous solution of 4-aminobenzoic acid $0.01 \mathrm{M}$ and $0.02 \mathrm{M}$ of sodium nitrite. Eventually, $1 \mu \mathrm{L}$ of the functionalized rGO dispersion was manually drop casted onto the WEs with a micro pipette (Gilson). The whole device was then dried at $110^{\circ} \mathrm{C}$ for $3 \mathrm{~h}$.

A Nafion ${ }^{\circledR}$ membrane was used to prevent any degradation phenomena of the $\mathrm{Ag} / \mathrm{AgCl}$ pseudo reference. Thus $0.5 \mu \mathrm{L}$ of Nafion® $5 \% 117$ (70160) (Sigma Aldrich) was manually casted onto the pseudo reference electrode surface. Nafion was then fixed by curing at $110^{\circ} \mathrm{C}$ for $30 \mathrm{~min}$.

\subsection{Bacterial strains and culture conditions}

A panel of Gram-negative and Gram-positive bacterial species represented by Escherichia coli (ATCC 25922), Pseudomonas aeruginosa (ATCC 15442) and Staphylococcus aureus (ATCC 12600) were used for the evaluation of the sensor's ability to monitor bacterial growth in both liquid and semisolid Luria Bertani (LB) culture media (Sigma Aldrich). LB was used as this should limit the influence of confounding factors linked to different selective media.

Strains were stored at $-20{ }^{\circ} \mathrm{C}$ and $-80{ }^{\circ} \mathrm{C}$ in LB supplemented with $40 \%$ glycerol $(\mathrm{v} / \mathrm{v})$. Bacteria were grown on LB agar and incubated overnight $(\mathrm{ON})$ at $37{ }^{\circ} \mathrm{C}$ when necessary. Bacterial pre- 
inoculum was prepared in $5 \mathrm{~mL}$ of fresh LB broth, from a single colony and incubated at $37^{\circ} \mathrm{C}$ under agitation at $220 \mathrm{rpm}$ ON.

Bacteria were grown in LB broth at $37^{\circ} \mathrm{C}$ for liquid cultures, and on LB semisolid agar $(0.75 \%$ agar) at $37^{\circ} \mathrm{C}$. For the enumeration of Colony Forming Units (CFU), the bacterial suspensions were serially diluted in phosphate buffered saline (PBS) $1 x$ and seeded on LB agar plates.

\subsection{Biofilm formation assessment}

Bacteria were evaluated for their ability to form biofilm in vitro. Briefly, for each species, a liquid overnight bacterial culture was 1:100 diluted in fresh LB broth, the bacterial suspension was then inoculated in polystyrene flat-bottom 96-well microtiter plates $(100 \mu \mathrm{L} /$ well $)$ and grown for 24 hours at $37^{\circ} \mathrm{C}$. After incubation, non-adhered cells were removed by washing twice with $1 \times$ PBS. Biofilm cellular density was measured as the optical density $(\mathrm{OD}, \lambda=490 \mathrm{~nm})$ using an automated plate reader (Microplate Reader Model 550, Bio-Rad, Milan, Italy). The background optical density was subtracted from values measured in each well, four replicates were performed.

Biofilm formation on the sensor substrate was also verified. The board was placed in an LB broth solution, inoculated with a bacterial suspension, and incubated at $37^{\circ} \mathrm{C}$ under constant agitation (220 $\mathrm{rpm}$ ). At different time points during bacterial growth, the board was removed, washed twice in PBS $1 \mathrm{x}$ and its surface gently scrapped to detach all adhered cells. Bacterial suspensions were then diluted in PBS 1x, grown on LB agar and incubated at $37^{\circ} \mathrm{C}$ for $24 \mathrm{~h}$ for the quantification of the CFUs. One experiment was performed for each strain.

\subsection{Assessment of sensor ability to monitor bacterial growth in liquid cultures}

A bacterial pre-inoculum, prepared as already described, was diluted in $100 \mathrm{~mL}$ of fresh LB broth to match a standardized optical density OD $(\lambda=600 \mathrm{~nm})$ corresponding to $10^{6} \mathrm{CFU} / \mathrm{mL}$. Then, a sterilized sensor board was positioned vertically and incubated at $37{ }^{\circ} \mathrm{C}$ under agitation at $220 \mathrm{rpm}$ in an orbital shaker. Microorganisms were grown for 6 hours at $37^{\circ} \mathrm{C}$, while the OCP between the WE and the RE was continuously monitored (every 15 minutes) using a potentiostat (Palmsens4, Palmsens). The bacterial culture OD $(\lambda=600 \mathrm{~nm})$ was measured hourly. Sterilized liquid LB culture media was also added as negative control. Three independent experiments, with four replicates each, were performed.

The bacterial generation time, i.e. the time required for a bacterial population to double in number, was determined from the growth curves and approximated from the OD doubling time observed during the exponential phase. To determine if the registered OCP value was due to the growth of bacterial cells on the sensor surface or the bulk culture, a representative E. coli ATCC 25922 culture aliquot was filtrated using a $0.22 \mu \mathrm{m}$ membrane filter and the OCP measured using a sterilized sensor. Three independent experiments were performed, each with four replicates.

\subsection{Assessment of sensor ability to monitor bacterial growth on semisolid culture media}

Previous experiments were replicated using an LB semisolid culture media. A standardized bacterial culture corresponding to $\sim 2 \times 10^{7} \mathrm{CFU} / \mathrm{mL}$ was prepared and plated on a LB semisolid agar plate $(0.75 \%$ agar). A sensor board was then placed in direct contact with the agar surface and incubated at $37^{\circ} \mathrm{C}$ for 6 hours. A control plate containing the sensor where no bacteria was inoculated was also prepared. The OCP was continuously registered (every 15 minutes), while the bacterial concentration on the agar surface was determined hourly. This procedure included the cutting of a $1 \mathrm{~cm}^{2}$ agar fragment, the transfer into a $50 \mathrm{~mL}$ tube containing $1 \mathrm{~mL}$ PBS $1 \mathrm{x}$ and $2.0 \mathrm{~mm}$ glass beads, and vortexing to break the agar and release the cells in suspension. Then the sample was serially diluted using PBS $1 \mathrm{x}$, plated on LB agar and incubated $\mathrm{ON}$ at $37^{\circ} \mathrm{C}$. Results were expressed as $\mathrm{CFU} / \mathrm{cm}^{2}$. Three independent experiments were performed, each with four replicates. A negative control was also included.

Bacterial generation time on semisolid LB was determined from the growth curves and approximated from the CFU doubling time.

\subsection{Data analysis}


Data were expressed as means $\pm \mathrm{SD}$. Correlation between the bacterial growth in liquid (OD $\lambda=600 \mathrm{~nm})$ and semisolid $\left(\mathrm{CFU} / \mathrm{cm}^{2}\right)$ culture media with respect to the sensor output $(\mathrm{mV})$ was analyzed with the non-parametric Spearman correlation test using the GraphPad Instat software (version 6.05 for Windows, La Jolla, CA, United States). The significance level was set to $p<0.05$.

\section{Results}

\subsection{Graphene oxide reduction and functionalization}

Characterization of graphene oxide reduced with L-ascorbic acid and functionalized with 4amminobenzoic acid (rGO-AB) has been described by Bonini et al. [46].

\subsection{Biofilm formation}

The biofilm biomass production was first evaluated by the 96 well plate standard assay. This confirmed that all strains included in the study were able to form biofilm in vitro in LB culture media (Figure 1A). Moreover, all strains colonized the sensor surface, as shown in Figure 1B for the $S$. aureus ATCC 12600 that was chosen as the representative strain (Figure 1B).
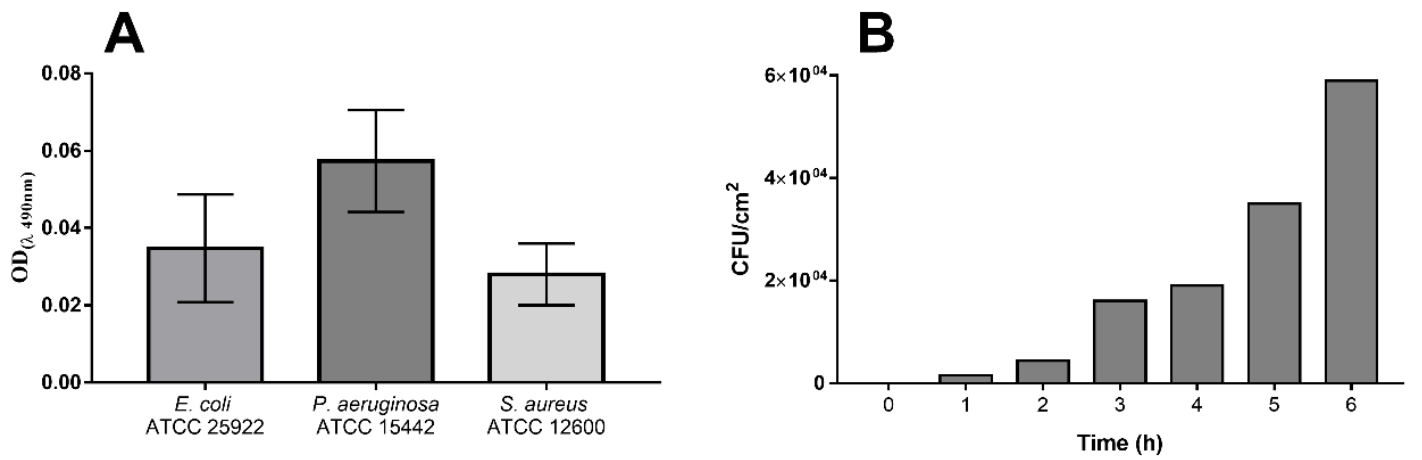

Figure 1. (a) Biofilm formation of the three reference strains, assessed by the 96 well plate assay and (b) biofilm formation on the sensor surface by S. aureus ATCC 12600

\subsection{Monitoring of bacterial growth on in liquid cultures media}

The OCP changed over time, shifting towards a negative potential value as bacteria grew. For all the bacteria here tested, a significant negative correlation was observed (Figure 2). Using this system, it was possible to distinguish the different phases of bacterial growth: the lag phase, characterized by a reduced growth where the potential remained quite stable, followed by a significant reduction of the OCP value corresponding to the exponential growth phase where bacteria actively proliferate, finally reaching a plateau equivalent to the stationary phase, where bacteria stop replicating as the nutrients of the media had been consumed. This last phase was more evident for $E$. coli, which entered the stationary phase earlier and grew faster than the other two bacterial species. The estimated generation times for E. coli, $P$. aeruginosa, and $S$. aureus were equal to 33,42 and 51 minutes, respectively. As expected, the registered $\mathrm{OCP}$ in the negative control did not change over time (data not shown). 

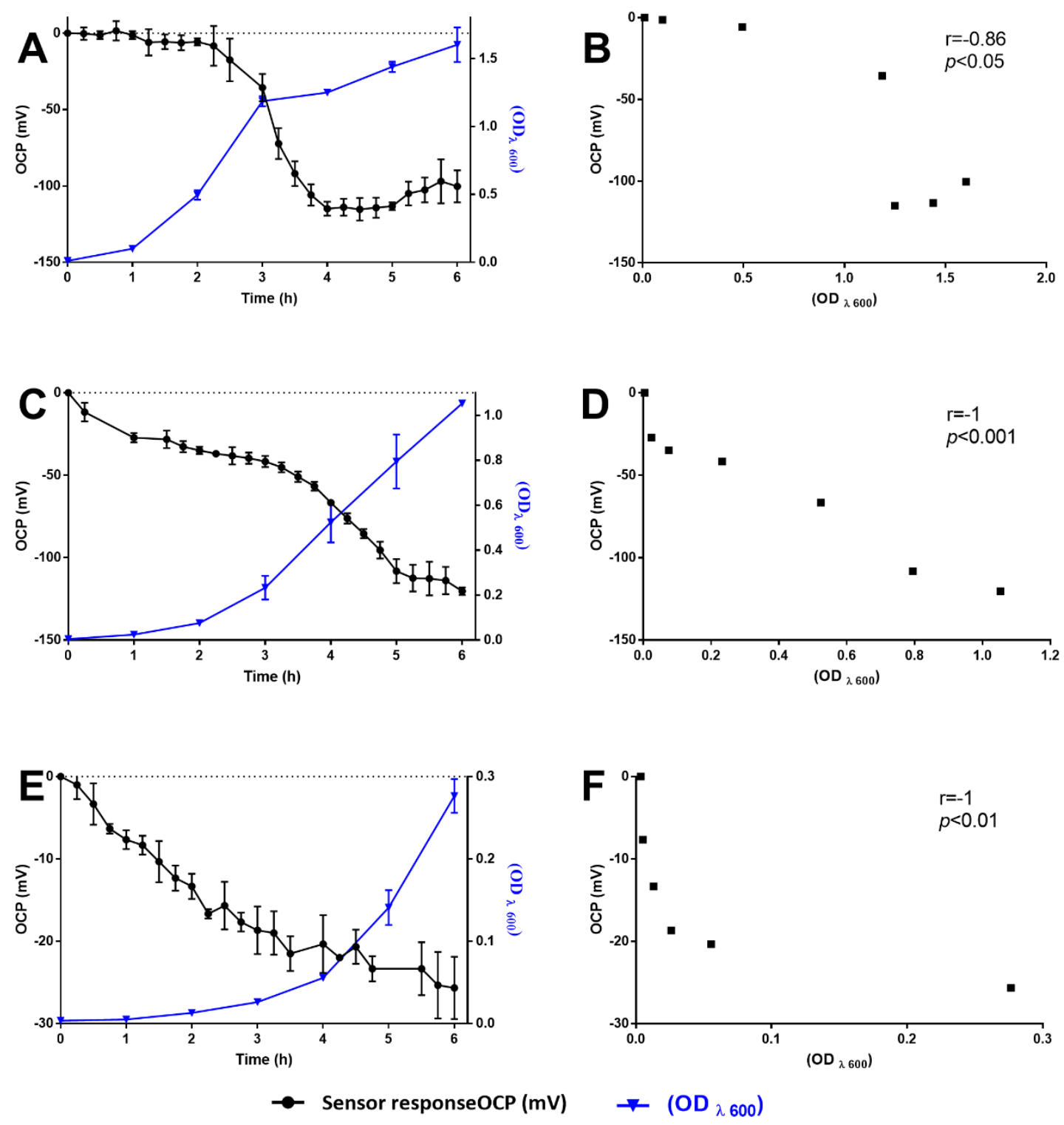

Figure 2. (a) OCP and OD values during bacterial growth in LB liquid cultures for $E$. coli ATCC 25922; (c) $P$. aeruginosa ATCC 15442; (e) S. aureus ATCC 12600. Sensor response (OCP) versus bacterial growth (OD): (b) E. coli ATCC 25922; (d) P. aeruginosa 15442 and (f) S. aureus ATCC 12600.

A further experiment was carried out to test if the registered OCP value mainly accounted for the bacterial growth on the electrode surface. The OCP measured in the filtered bacterial culture of $E$. coli ATCC 25922 remained stable over time: it did not follow the growth curve and did not show any significant correlation with the bacterial culture OD ( $r=-0.04, P=0.96)$ (Figure 3). Therefore, this system was able to monitor a localized change directly related to the biofilm growth on the electrode surface. 


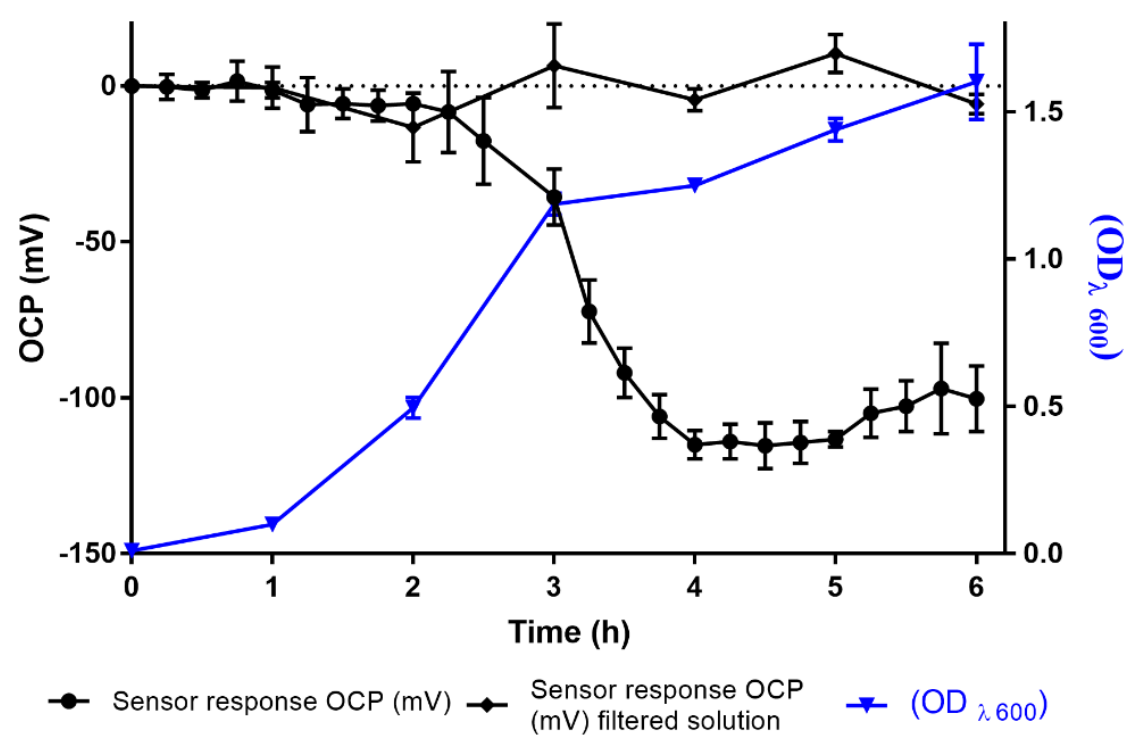

Figure 3. E. coli ATCC 25922 growth monitoring in LB liquid culture media, measured as the OCP (filtered and non-filtered solution) and the optical density (non-filtered solution).

\subsection{Monitoring of bacterial growth on semi-solid culture media}

As in previous experiments, the sensor response on the semi-solid agar surface was shown to change concomitantly to the bacterial growth expressed in $\mathrm{CFU} / \mathrm{cm}^{2}$; indeed, as the bacterial concentration increased, the OCP value decreased exhibiting a significant negative correlation in all cases (Figure 4). The lag and logarithmic phases were observed in the OCP curve for $E$. coli and $S$. aureus, but not for $P$. aeruginosa, whose sensor response linearly decreased from the first measurement. During the monitoring time (6 hours), all bacteria entered the logarithmic phase, except $E$. coli, which grew faster and reached the early stationary phase in accordance to the calculated generation times: 36,46 , and 55 minutes for E. coli, $P$. aeruginosa and $S$. aureus, respectively. In general, these values were higher than those registered from bacteria growing in the LB liquid media.

The OCP value in the negative control did not change over time (data not shown), which demonstrated its association to the processes occurring during bacterial growth. 

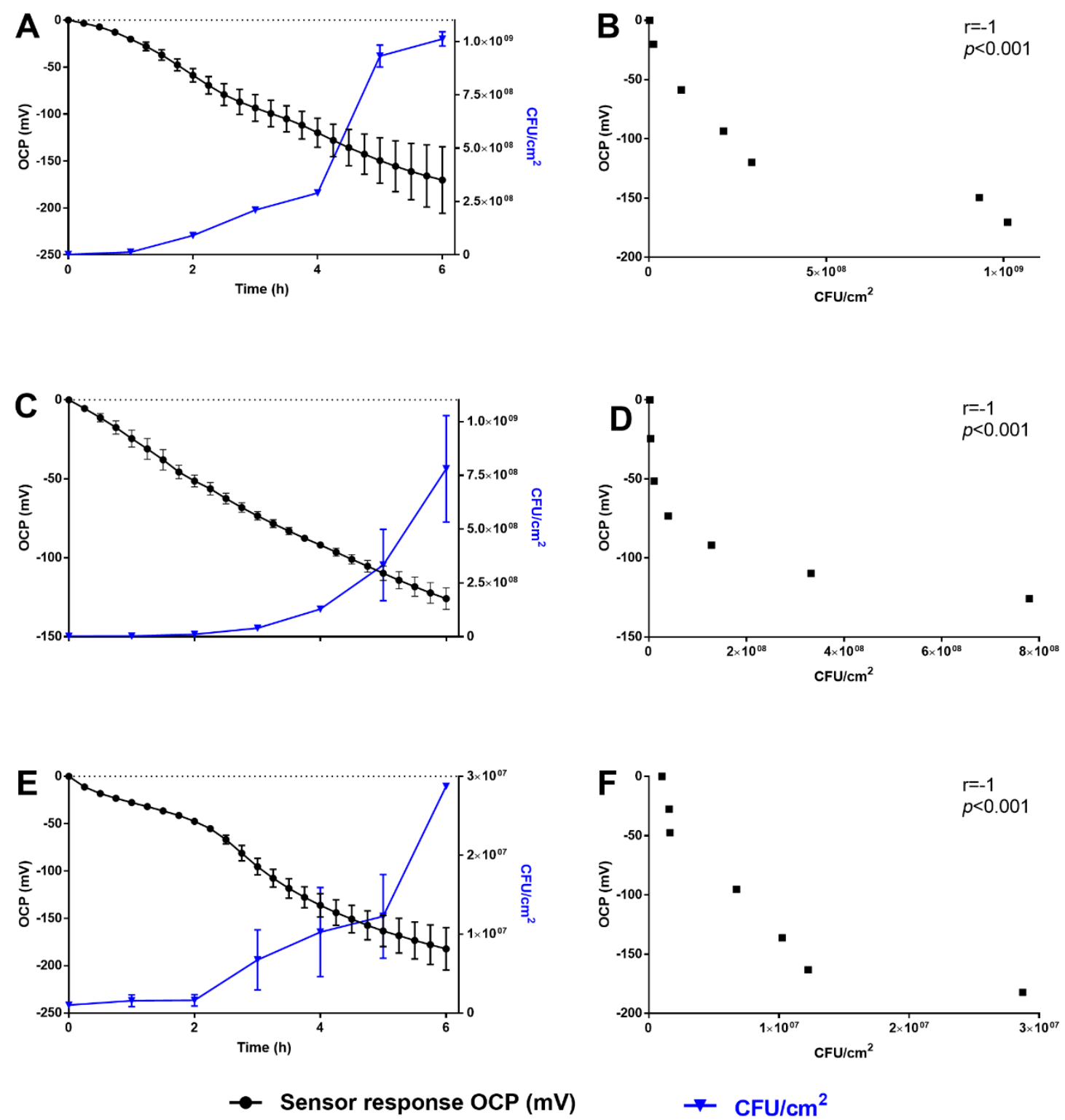

Figure 4. (a) OCP values measured during bacterial growth on LB semisolid culture media: (a) E. coli ATCC 25922; (c) P. aeruginosa 15442; (e) S. aureus ATCC 12600. Sensor response (OCP) versus bacterial growth (OD): (b) E. coli ATCC 25922; (d) P. aeruginosa 15442 and (f) S. aureus ATCC 12600.

\section{Discussion}

Biofilms are dynamic structures, constantly changing over time $[48,49]$. Their important role in the onset of infections or sepsis urged the scientific community to develop new technologies for an early detection. Sensors susceptible to changes at the electrode surface and surrounding environment are amongst the most interesting tools described in literature for this aim due to the promise of a continuous monitoring. The sensor device described in this paper used rGO-AB as the sensing material and OCP measurement as transduction method; its performances were assessed with bacteria growing both in liquid and semisolid LB culture media.

rGO-AB was selected as the sensing material because rGO is highly conductive and known to promote the exchange of electrons with bacteria [50], which is convenient in combination with OCP measurements to detect bacterial growth. The presence of a limited number of residual defects upon the chemical reduction of graphene oxide does not impair the electrical conductivity. At the same time, defects provide reactive moieties such as the hydroxyl $(\mathrm{OH})$ and carboxyl $(\mathrm{COOH})$ groups that foster bacterial adhesion and electron transfer [51,52,53]. Furthermore, $\mathrm{rGO}$ can be easily 
functionalized to improve sensor performance in different matrices [52,53]; in this case, the functionalization with 4-aminobenzoic acid was chosen to increase the number of carboxylic groups on the electrode surface and improve the sensitivity of the device [46].

Due to the extremely low currents flowing between working and reference electrode, OCP measurement is an almost ideal electrochemical transduction technique for biofilm monitoring due to its negligible effects on bacteria and electrode surface [54]. OCP results from contributions of different processes taking place at the electrode/solution interface, such as the accumulation of charge and the spontaneous and simultaneously occurring reactions between the working electrode and compounds in the surrounding environment, which establish an intermediate potential between cathodic and anodic reactions [55]. This study showed a negative correlation between bacterial growth on the working electrode surface and OCP, with a significant reduction of this latter during the exponential phase. Previous studies demonstrated that the direction of the potential change depends on the microorganism, the material where the biofilm develops and the environment $[42,56]$. Here, the OCP shift towards more negative values as the bacterial concentration increases may be explained by the interaction of a variety of factors. An increase in the cell biomass may account for a larger number of negative charges on the working electrode surface. Both Gram-positive and Gramnegative bacteria, although different in composition, have a negative net charge on the cell wall, which contains carboxyl, amide, hydroxyl, phosphate and carbohydrate related moieties [58,59]. The presence of negatively charged biomolecules such as DNA, proteins and others present in the extracellular polymeric substance may also contribute to the accumulation of charges [58]. Indeed, a closer interaction of DNA and negatively charged biomolecules with the electrode surface was associated to a decrease in the OCP value in an aptamer based biosensor detecting the prostate specific antigen (PSA) [59,60], which was also negatively correlated to the amount of added antigen [60].

Another factor to be considered is the direct and constant release of products of bacterial metabolism. Bacterial physiology is dependent on the bacterial species and the culture medium composition; in the present study, we used a non-selective LB medium containing tryptone and yeast extract as a source of oligopeptides, aminoacids, sugars, lipids, vitamins, and carbohydrates [61]. As proposed in previous studies using $E$. coli as a model organism, catabolizable aminoacids are the principal carbon source in this culture media, and are sequentially consumed $[61,62]$. During their metabolism, these are deaminated by membrane associated proteins such as aminoacid dehydrogenases and transaminases, so that ammonia $\left(\mathrm{NH}_{3}\right)$ is produced; ammonia is then protonated to ammonium $\left(\mathrm{NH}_{4}{ }^{+}\right)$with the consequent formation of hydroxide ions, which may further contribute to the charge accumulation on the WE $[61,63]$. However, it should also be considered that sessile cells embedded within the biofilm community vary greatly and that only a few of different bacterial subpopulations may be metabolically active [48]. Variations in the OCP have also been attributed to changes in the environment properties due to bacterial growth. For example, the depletion of oxygen on a steel working electrode surface associated to the growth of Pseudomonas fragi and E. coli in LB culture media decreased the OCP [64].

Microbial respiration and the associated redox processes in electroactive biofilms (EABs) could also modify OCP. Microorganisms within EABs exchange electrons with the electrodes thanks to bacterial surface components (e.g. outer membrane proteins) or redox mediators [65-67]. Pocaznoi et al. found that the growth of a consortium of soil microorganisms forming a biofilm on the surface of a carbon cloth electrode decreased the OCP, and this behavior was explained by the presence of an $E A B$ and the depletion of oxygen at the electrode surface, resulting in a slow oxidation of the surface [68].

E. coli and $P$. aeruginosa, two of the bacterial strains used in this study, have been reported as electrochemically active [69]; their main electron transfer mechanism is associated to the use of electron mediators: metabolites for $E$. coli [70], and phenazine derivatives for $P$. aeruginosa [71]. Little is known about the electrochemical activity for $S$. aureus. In 2010, Cournet and colleagues studied the catalysis of the electrochemical reduction of oxygen by different bacteria including S. aureus, which demonstrated not to have this ability [72]. However, other aforementioned processes may contribute to the OCP variation. 
Bacterial generation time is not constant among microorganisms, as it depends on the microorganism and the characteristics of the surrounding environment (e.g. temperature, availability of nutrients). Under the experimental conditions here used, it was estimated that bacteria growing in LB liquid culture media grew faster than their counterparts in semisolid culture. In general, generation times were higher for $S$. aureus and lower for $E$. coli. This was reflected in the sensor response, which stabilized once $E$. coli reached the stationary phase.

Interestingly, although the growth rate of bacteria was lower in semisolid culture media, a sudden decrease of the OCP was observed, so in some cases the lag phase was not well differentiated. It should be considered that prior to biofilm formation, planktonic cells have first to get close to the surface. In liquid media for example, this process is mediated by active (i.e. bacterial swimming) and passive (i.e. precipitation and convection-diffusion) movements [73,74]. In our study, bacteria in the semisolid medium were in direct contact with the working electrode surface, so this physical proximity likely allowed cells to circumvent this step and made it somehow easier for them to colonize the working electrode. On the contrary, the constant movement due to stirring and the vertical position of the sensor may have delayed the adhesion in liquid LB. Moreover, bacteria are just weakly attached to the surface during the early stages of biofilm formation [75], so that the initially suspended bacteria may have attached and detached from the surface several times before that a small fraction could irreversibly adhere and start replicating. This may account for the longer lag phase shown by the OCP in the liquid culture.

Our device is not selective, but biofilms are typically complex polymicrobial structures including different species whose composition may change over time, so we wonder if selectivity is really an issue or if the lack of selectivity may be considered an advantage in many applications. Considering the rapid and worrisome development of biofilms leading to Bls, this sensor could be exactly what needed to monitor the overall bacterial burden in wounds or to provide an early alert of microbial colonization in catheters, avoiding the undesired effects related to the progression of an infection.

\section{Conclusions}

This study described the development of a flexible, low-cost, biocompatible graphenic sensor allowing a real-time monitoring of the growth of common Gram-negative and Gram-positive bacteria involved in the development of Bls. The OCP used as the transduction technique efficiently detected biofilm growth localized on the sensor surface in liquid and semisolid culture media, and exhibited a significant negative correlation with respect to the bacterial growth. Biofilms are complex in nature, so the interaction of a variety of factors at the electrode surface may determine the OCP change over time. It was hypothesized that processes like the accumulation of a net negative charge, bacterial metabolism and respiration may account for the OCP decrease.

The assessment of bacterial growth and the OCP response in presence of inhibitors of metabolism, or the use disrupting compounds such as antimicrobial peptides in preformed biofilms, will certainly give in future further information about the processes causing the OCP variations. In addition, the use of other electrochemical techniques such as impedance spectroscopy may allow a deeper characterization of this system.

The sensor presented in this study may be potentially applied as a bacterial growth monitoring tool. Thanks to its flexibility, it could be embedded in smart dressings or catheters for a timely detection of biofilms formed by bacterial species of clinical importance.

Acknowledgments: This research was funded by Fondazione Pisa through the SEMPRE project. The Center for the Integration of Scientific instrumentation of the University of Pisa (CISUP) is also gratefully acknowledged for its help in the characterization and quality control of the electrodes.

\section{References}

[1] R.M. Donlan, Biofilm Formation: A Clinically Relevant Microbiological Process, Clin. Infect. Dis. 33 (2001) 1387-1392. doi:10.1086/322972.

[2] G. Gebreyohannes, A. Nyerere, C. Bii, D.B. Sbhatu, Challenges of intervention, treatment, and antibiotic resistance of biofilm-forming microorganisms, Heliyon. 5 (2019). doi:10.1016/j.heliyon.2019.e02192. 
Z. Khatoon, C.D. McTiernan, E.J. Suuronen, T.F. Mah, E.I. Alarcon, Bacterial biofilm formation on implantable devices and approaches to its treatment and prevention, Heliyon. 4 (2018). doi:10.1016/j.heliyon.2018.e01067.

[4] M. Jamal, W. Ahmad, S. Andleeb, F. Jalil, M. Imran, M.A. Nawaz, T. Hussain, M. Ali, M. Rafiq, M.A. Kamil, Bacterial biofilm and associated infections, J. Chinese Med. Assoc. 81 (2018) 7-11. doi:10.1016/j.jcma.2017.07.012.

[5] M. Gominet, F. Compain, C. Beloin, D. Lebeaux, Central venous catheters and biofilms: where do we stand in 2017?, Apmis. 125 (2017) 365-375. doi:10.1111/apm.12665.

[6] R.M. Donlan, Biofilms and device-associated infections, in: Emerg. Infect. Dis., 2001: pp. $277-281$. doi:10.3201/eid0702.010226.

[7] D.J. Davidson, D. Spratt, A.D. Liddle, Implant materials and prosthetic joint infection: The battle with the biofilm, EFORT Open Rev. 4 (2019) 633-639. doi:10.1302/2058-5241.4.180095.

[8] H.O. Gbejuade, A.M. Lovering, J.C. Webb, The role of microbial biofilms in prosthetic joint infections: A review, Acta Orthop. 86 (2015) 147-158. doi:10.3109/17453674.2014.966290.

[9] R.A. Brady, J.G. Leid, J.H. Calhoun, J.W. Costerton, M.E. Shirtliff, Osteomyelitis and the role of biofilms in chronic infection, FEMS Immunol. Med. Microbiol. 52 (2008) 13-22. doi:10.1111/j.1574695X.2007.00357.x.

[10] C. Attinger, R. Wolcott, Clinically Addressing Biofilm in Chronic Wounds, Adv. Wound Care. 1 (2012) 127-132. doi:10.1089/wound.2011.0333.

[11] G.A. James, E. Swogger, R. Wolcott, E.D. Pulcini, P. Secor, J. Sestrich, J.W. Costerton, P.S. Stewart, Biofilms in chronic wounds, Wound Repair Regen. 16 (2008) 37-44. doi:10.1111/j.1524475X.2007.00321.x.

[12] A. Clinton, T. Carter, Chronic Wound Biofilms: Pathogenesis and Potential Therapies, Lab. Med. 46 (2015) 277-284. doi:10.1309//mbnswkui4jpn7so.

[13] P.K. Singh, A.L. Schaefer, M.R. Parsek, T.O. Moninger, M.J. Welsh, E.P. Greenberg, Quorum-sensing signals indicate that cystic fibrosis lungs are infected with bacterial biofilms, Nature. 407 (2000) 762764. doi:10.1038/35037627.

[14] A. Kumar, A. Alam, M. Rani, N.Z. Ehtesham, S.E. Hasnain, Biofilms: Survival and defense strategy for pathogens, Int. J. Med. Microbiol. 307 (2017) 481-489. doi:10.1016/j.jmm.2017.09.016.

[15] J.L. Del Pozo, Biofilm-related disease, Expert Rev. Anti. Infect. Ther. 16 (2018) 51-65. doi:10.1080/14787210.2018.1417036.

[16] H. Wu, C. Moser, H.Z. Wang, N. Høiby, Z.J. Song, Strategies for combating bacterial biofilm infections, Int. J. Oral Sci. 7 (2015) 1-7. doi:10.1038/ijos.2014.65.

[17] D. Metcalf, P. Bowler, Biofilm delays wound healing: A review of the evidence, Burn. Trauma. 1 (2013) 5. doi:10.4103/2321-3868.113329.

[18] R.O. Darouiche, Device-Associated Infections: A Macroproblem that Starts with Microadherence, Clin. Infect. Dis. 33 (2001) 1567-1572. doi:10.1086/323130.

[19] L.A. Mermel, L. Mermel, B. Hudson, Prevention of intravascular catheter-related infections, Ann. Intern. Med. 132 (2000) 391-402. doi:10.7326/0003-4819-132-5-200003070-00009.

[20] U. Römling, C. Balsalobre, Biofilm infections, their resilience to therapy and innovative treatment strategies, J. Intern. Med. 272 (2012) 541-561. doi:10.1111/joim.12004.

[21] L. Hall-Stoodley, P. Stoodley, S. Kathju, N. Høiby, C. Moser, J. William Costerton, A. Moter, T. Bjarnsholt, Towards diagnostic guidelines for biofilm-associated infections, FEMS Immunol. Med. Microbiol. 65 (2012) 127-145. doi:10.1111/j.1574-695X.2012.00968.x. 
[22] M.D. Macià, J.L. del Pozo, M. Díez-Aguilar, J. Guinea, Microbiological diagnosis of biofilm-related infections, Enferm. Infecc. Microbiol. Clin. 36 (2018) 375-381. doi:10.1016/j.eimc.2017.04.006.

[23] S. Malic, K.E. Hill, A. Hayes, S.L. Percival, D.W. Thomas, D.W. Williams, Detection and identification of specific bacteria in wound biofilms using peptide nucleic acid fluorescent in situ hybridization (PNA FISH), Microbiology. 155 (2009) 2603-2611. doi:10.1099/mic.0.028712-0.

[24] C. Almeida, N.F. Azevedo, S. Santos, C.W. Keevil, M.J. Vieira, Discriminating multi-species populations in biofilms with peptide nucleic acid fluorescence in situ hybridization (PNA FISH), PLoS One. 6 (2011). doi:10.1371/journal.pone.0014786.

[25] Y. Song, N. Talaty, K. Datsenko, B.L. Wanner, R.G. Cooks, In vivo recognition of Bacillus subtilis by desorption electrospray ionization mass spectrometry (DESI-MS), Analyst. 134 (2009) 838-841. doi:10.1039/b900069k.

[26] P. Caputo, M.C. Di Martino, B. Perfetto, F. Iovino, G. Donnarumma, Use of MALDI-TOF MS to discriminate between biofilm-producer and non-producer strains of staphylococcus epidermidis, Int. J. Environ. Res. Public Health. 15 (2018). doi:10.3390/ijerph15081695.

[27] A.M. Gaudreau, J. Labrie, C. Goetz, S. Dufour, M. Jacques, Evaluation of MALDI-TOF mass spectrometry for the identification of bacteria growing as biofilms, J. Microbiol. Methods. 145 (2018) 7981. doi:10.1016/j.mimet.2018.01.003.

[28] A. Vertes, V. Hitchins, K.S. Phillips, Analytical challenges of microbial biofilms on medical devices, Anal. Chem. 84 (2012) 3858-3866. doi:10.1021/ac2029997.

[29] M. Fischer, M. Wahl, G. Friedrichs, Design and field application of a UV-LED based optical fiber biofilm sensor, Biosens. Bioelectron. 33 (2012) 172-178. doi:10.1016/j.bios.2011.12.048.

[30] Y. Kurmoo, A.L. Hook, D. Harvey, J.-F. Dubern, P. Williams, S.P. Morgan, S. Korposh, M.R. Alexander, Real time monitoring of biofilm formation on coated medical devices for the reduction and interception of bacterial infections, Biomater. Sci. (2020). doi:10.1039/c9bm00875f.

[31] J.S. Kee, S.Y. Lim, A.P. Perera, Y. Zhang, M.K. Park, Plasmonic nanohole arrays for monitoring growth of bacteria and antibiotic susceptibility test, Sensors Actuators, B Chem. 182 (2013) 576-583. doi:10.1016/j.snb.2013.03.053.

[32] H. Beyenal, C. Yakymyshyn, J. Hyungnak, C.C. Davis, Z. Lewandowski, An optical microsensor to measure fluorescent light intensity in biofilms, J. Microbiol. Methods. 58 (2004) 367-374. doi:10.1016/j.mimet.2004.05.003.

[33] M. Fischer, G.J. Triggs, T.F. Krauss, Optical Sensing of Microbial Life on Surfaces, Appl. Environ. Microbiol. (2016). doi:10.1128/aem.03001-15.

[34] M. Strathmann, K.H. Mittenzwey, G. Sinn, W. Papadakis, H.C. Flemming, Simultaneous monitoring of biofilm growth, microbial activity, and inorganic deposits on surfaces with an in situ, online, real-time, non-destructive, optical sensor, Biofouling. (2013). doi:10.1080/08927014.2013.791287.

[35] N.T. Thet, D.R. Alves, J.E. Bean, S. Booth, J. Nzakizwanayo, A.E.R. Young, B. V. Jones, A.T.A. Jenkins, Prototype Development of the Intelligent Hydrogel Wound Dressing and Its Efficacy in the Detection of Model Pathogenic Wound Biofilms, ACS Appl. Mater. Interfaces. 8 (2016) 14909-14919. doi:10.1021/acsami.5b07372.

[36] C.C. Liu, Electrochemical sensors, in: Med. Devices Syst., 2006: pp. 48-1-48-6.

[37] X. Muñoz-Berbel, F.J. Muñoz, N. Vigués, J. Mas, On-chip impedance measurements to monitor biofilm formation in the drinking water distribution network, Sensors Actuators, B Chem. 118 (2006) 129-134. doi:10.1016/j.snb.2006.04.070.

[38] J. Paredes, S. Becerro, S. Arana, Label-free interdigitated microelectrode based biosensors for bacterial 
biofilm growth monitoring using Petri dishes, J. Microbiol. Methods. 100 (2014) 77-83. doi:10.1016/j.mimet.2014.02.022.

[39] R.C. Huiszoon, S. Subramanian, P. Ramiah Rajasekaran, L.A. Beardslee, W.E. Bentley, R. Ghodssi, Flexible Platform for In Situ Impedimetric Detection and Bioelectric Effect Treatment of Escherichia coli Biofilms, IEEE Trans. Biomed. Eng. 66 (2019) 1337-1345. doi:10.1109/TBME.2018.2872896.

[40] J. Kang, T. Kim, Y. Tak, J.H. Lee, J. Yoon, Cyclic voltammetry for monitoring bacterial attachment and biofilm formation, J. Ind. Eng. Chem. 18 (2012) 800-807. doi:10.1016/j.jiec.2011.10.002.

[41] D.L. Bellin, H. Sakhtah, J.K. Rosenstein, P.M. Levine, J. Thimot, K. Emmett, L.E.P. Dietrich, K.L. Shepard, Integrated circuit-based electrochemical sensor for spatially resolved detection of redox-active metabolites in biofilms, Nat. Commun. 5 (2014) 3256. doi:10.1038/ncomms4256.

[42] P. Gümpel, N. Arlt, J. Telegdi, D. Schiller, O. Moos, Microbiological influence on the electro-chemical potential of stainless steel, Mater. Corros. 57 (2006) 715-723. doi:10.1002/maco.200503962.

[43] K. Mattila, L. Carpen, T. Hakkarainen, M.S. Salkinoja-Salonen, Biofilm development during ennoblement of stainless steel in Baltic Sea water: A microscopic study, Int. Biodeterior. Biodegrad. 40 (1997) 1-10. doi:10.1016/S0964-8305(97)00003-6.

[44] X. Guimer, A. Moya, A.D. Dorado, X. Illa, R. Villa, D. Gabriel, X. Gamisan, G. Gabriel, A minimally invasive microsensor specially designed for simultaneous dissolved oxygen and $\mathrm{pH}$ biofilm profiling, Sensors (Switzerland). 19 (2019). doi:10.3390/s19214747.

[45] P. Salvo, N. Calisi, B. Melai, B. Cortigiani, M. Mannini, A. Caneschi, G. Lorenzetti, C. Paoletti, T. Lomonaco, A. Paolicchi, I. Scataglini, V. Dini, M. Romanelli, R. Fuoco, F. Di Francesco, Temperature and $\mathrm{pH}$ sensors based on graphenic materials, Biosens. Bioelectron. 91 (2017) 870-877. doi:10.1016/j.bios.2017.01.062.

[46] A. Bonini, F. Di Francesco, P. Salvo, F. Vivaldi, E. Herrera, B. Melai, A. Kirchhain, N. Poma, M. Mattonai, R. Caprioli, T. Lomonaco, A Graphenic Biosensor for Real-Time Monitoring of Urea during Dialysis, IEEE Sens. J. (2020) 1-1. doi:10.1109/jsen.2020.2966456.

[47] E.G. Herrera, A. Bonini, F. Vivaldi, B. Melai, P. Salvo, N. Poma, D. Santalucia, A. Kirchhain, F. Di Francesco, A Biosensor for the Detection of Acetylcholine and Diazinon, in: Proc. Annu. Int. Conf. IEEE Eng. Med. Biol. Soc. EMBS, 2019: pp. 1159-1162. doi:10.1109/EMBC.2019.8856959.

[48] H.-C. Flemming, J. Wingender, U. Szewzyk, P. Steinberg, S.A. Rice, S. Kjelleberg, Biofilms: an emergent form of bacterial life., Nat. Rev. Microbiol. 14 (2016) 563-75. doi:10.1038/nrmicro.2016.94.

[49] D. López, H. Vlamakis, R. Kolter, Biolims, Cold Spring Harb Perspect Biol. 2 (2010) 1-11. doi:10.1101/cshperspect.a000398.

[50] Y. Zhang, G. Mo, X. Li, W. Zhang, J. Zhang, J. Ye, X. Huang, C. Yu, A graphene modified anode to improve the performance of microbial fuel cells, J. Power Sources. 196 (2011) 5402-5407. doi:10.1016/j.jpowsour.2011.02.067.

[51] S. Cheng, B.E. Logan, Ammonia treatment of carbon cloth anodes to enhance power generation of microbial fuel cells, Electrochem. Commun. 9 (2007) 492-496. doi:10.1016/j.elecom.2006.10.023.

[52] N. Poma, F. Vivaldi, A. Bonini, N. Carbonaro, F. Di Rienzo, B. Melai, A. Kirchhain, P. Salvo, A. Tognetti, F. Di Francesco, Remote monitoring of seawater temperature and $\mathrm{pH}$ by low cost sensors, Microchem. J. 148 (2019) 248-252. doi:10.1016/j.microc.2019.05.001.

[53] F. Vivaldi, A. Bonini, B. Melai, N. Poma, A. Kirchhain, D. Santalucia, P. Salvo, F. Di Francesco, A graphene-based $\mathrm{pH}$ sensor on paper for human plasma and seawater, in: Proc. Annu. Int. Conf. IEEE Eng. Med. Biol. Soc. EMBS, 2019: pp. 1563-1566. doi:10.1109/EMBC.2019.8856991.

[54] P. Janknecht, L.F. Melo, Online biofilm monitoring, Rev. Environ. Sci. Biotechnol. 2 (2003) $269-283$. 
doi:10.1023/B:RESB.0000040461.69339.04.

[55] V.S. Bagotsky, Fundamentals of Electrochemistry: Second Ed., 2005. doi:10.1002/047174199X.

[56] F. Trigodet, N. Larché, H.G. Morrison, M. Jebbar, D. Thierry, L. Maignien, Electroactive bacteria associated with stainless steel ennoblement in seawater, Front. Microbiol. 10 (2019). doi:10.3389/fmicb.2019.00170.

[57] W. Jiang, A. Saxena, B. Song, B.B. Ward, T.J. Beveridge, S.C.B. Myneni, Elucidation of functional groups on gram-positive and gram-negative bacterial surfaces using infrared spectroscopy, Langmuir. 20 (2004) 11433-11442. doi:10.1021/la049043+.

[58] S.S. Branda, Å. Vik, L. Friedman, R. Kolter, Biofilms: The matrix revisited, Trends Microbiol. 13 (2005) 20-26. doi:10.1016/j.tim.2004.11.006.

[59] P. Estrela, D. Paul, P. Li, S.D. Keighley, P. Migliorato, S. Laurenson, P.K. Ferrigno, Label-free detection of protein interactions with peptide aptamers by open circuit potential measurement, Electrochim. Acta. 53 (2008) 6489-6496. doi:10.1016/j.electacta.2008.04.036.

[60] L.C.C. Wong, P. Jolly, P. Estrela, Development of a Sensitive Multiplexed Open Circuit Potential System for the Detection of Prostate Cancer Biomarkers, Bionanoscience. 8 (2018) 701-706. doi:10.1007/s12668-017-0408-0.

[61] G. Sezonov, D. Joseleau-Petit, R. D’Ari, Escherichia coli physiology in Luria-Bertani broth, J. Bacteriol. 189 (2007) 8746-8749. doi:10.1128/JB.01368-07.

[62] B.M. Prub, J.M. Nelms, C. Park, A.J. Wolfe, Mutations in NADH: Ubiquinone oxidoreductase of Escherichia coli affect growth on mixed amino acids, J. Bacteriol. 176 (1994) 2143-2150. doi:10.1128/jb.176.8.2143-2150.1994.

[63] B. Ibarlucea, T. Rim, C.K. Baek, J.A.G.M. De Visser, L. Baraban, G. Cuniberti, Nanowire sensors monitor bacterial growth kinetics and response to antibiotics, Lab Chip. 17 (2017) 4283-4293. doi:10.1039/c7lc00807d.

[64] A. Jayaraman, E.T. Cheng, J.C. Earthman, T.K. Wood, Axenic aerobic biofilms inhibit corrosion of SAE 1018 steel through oxygen depletion, Appl. Microbiol. Biotechnol. 48 (1997) 11-17. doi:10.1007/s002530051007.

[65] K. Rabaey, W. Verstraete, Microbial fuel cells: Novel biotechnology for energy generation, Trends Biotechnol. 23 (2005) 291-298. doi:10.1016/j.tibtech.2005.04.008.

[66] I.S. Chang, H. Moon, O. Bretschger, J.K. Jang, H. II Park, K.H. Nealson, B.H. Kim, Electrochemically active bacteria (EAB) and mediator-less microbial fuel cells, J. Microbiol. Biotechnol. 16 (2006) 163-177.

[67] J. Babauta, R. Renslow, Z. Lewandowski, H. Beyenal, Electrochemically active biofilms: Facts and fiction. A review, Biofouling. 28 (2012) 789-812. doi:10.1080/08927014.2012.710324.

[68] D. Pocaznoi, B. Erable, L. Etcheverry, M.L. Delia, A. Bergel, Forming microbial anodes under delayed polarisation modifies the electron transfer network and decreases the polarisation time required, Bioresour. Technol. 114 (2012) 334-341. doi:10.1016/j.biortech.2012.03.042.

[69] A. Sydow, T. Krieg, F. Mayer, J. Schrader, D. Holtmann, Electroactive bacteria—molecular mechanisms and genetic tools, Appl. Microbiol. Biotechnol. 98 (2014) 8481-8495. doi:10.1007/s00253-014-6005-z.

[70] T. Zhang, C. Cui, S. Chen, H. Yang, P. Shen, The direct electrocatalysis of Escherichia coli through electroactivated excretion in microbial fuel cell, Electrochem. Commun. 10 (2008) 293-297. doi:10.1016/j.elecom.2007.12.009.

[71] K. Rabaey, N. Boon, M. Höfte, W. Verstraete, Microbial phenazine production enhances electron transfer in biofuel cells, Environ. Sci. Technol. 39 (2005) 3401-3408. doi:10.1021/es048563o.

[72] A. Cournet, M.L. Délia, A. Bergel, C. Roques, M. Bergé, Electrochemical reduction of oxygen catalyzed 
by a wide range of bacteria including Gram-positive, Electrochem. Commun. 12 (2010) 505-508. doi:10.1016/j.elecom.2010.01.026.

[73] C. Berne, C.K. Ellison, A. Ducret, Y. V. Brun, Bacterial adhesion at the single-cell level, Nat. Rev. Microbiol. 16 (2018) 616-627. doi:10.1038/s41579-018-0057-5.

[74] V. Carniello, B.W. Peterson, H.C. van der Mei, H.J. Busscher, Physico-chemistry from initial bacterial adhesion to surface-programmed biofilm growth, Adv. Colloid Interface Sci. 261 (2018) 1-14. doi:10.1016/j.cis.2018.10.005.

[75] K. Hori, S. Matsumoto, Bacterial adhesion: From mechanism to control, Biochem. Eng. J. 48 (2010) 424434. doi:10.1016/j.bej.2009.11.014. 